\title{
Calving management practices on Canadian dairy farms: Prevalence of practices
}

\author{
M. Villettaz Robichaud, ${ }^{* 1}$ A. M. de Passillé,† D. L. Pearl, ${ }^{*}$ S. J. LeBlanc, ${ }^{\star}$ S. M. Godden,‡ D. Pellerin,§ \\ E. Vasseur,\# J. Rushen,† and D. B. Haley* \\ *Department of Population Medicine, Ontario Veterinary College, University of Guelph, Guelph, Ontario, Canada, N1G 2W1 \\ †Dairy Education and Research Centre, University of British Columbia, Agassiz, British Columbia, Canada, V0M 1A2 \\ fDepartment of Veterinary Population Medicine, University of Minnesota, St. Paul 55108 \\ §Department of Animal Science, University Laval, Québec, Québec, Canada, G1V OA6 \\ \#Organic Dairy Research Center, University of Guelph, Alfred Campus, Alfred, Ontario, Canada, K0B 1A0
}

\section{ABSTRACT}

Little information is available about current practices around calving in dairy cattle. The aim of this study was to describe calving management practices in the Canadian dairy industry related to housing, calving protocols, monitoring of parturition, and calving assistance. Information was gathered by in-person interviews from 236 dairy farms from 3 Canadian provinces (Alberta, Ontario, and Québec) with freestalls and an automatic milking system $(\mathrm{n}=24)$, freestalls with a parlor $(\mathrm{n}$ $=112)$, and tiestalls $(\mathrm{n}=100)$. The most commonly used types of calving facilities were group calving pens (35\%) followed by individual calving pens (30\%). Tiestalls were used by $26 \%$ of all surveyed producers as their main type of calving area (49\% of the tiestall, $7 \%$ of the freestall with parlor, and $13 \%$ of the automatic milking system farms). Written protocols related to calving were found on only $7 \%$ of the farms visited, and only $50 \%$ of those protocols were developed with a veterinarian. However, 90\% of producers kept written records of calving difficulty. Monitoring of cows around calving occurred 5 times more often during the daytime (between morning and evening milking) compared with nighttime. Cameras were used to monitor cows around and during calvings on $18 \%$ of farms. Sixteen percent of producers vaginally palpated all animals during calving. Twenty-seven percent of producers interviewed assisted all calvings on their farms by pulling the calf, and $37 \%$ assisted all heifers at calving. According to the producers' reported perception, $93 \%$ of them had "a minor problem" or "no problem" with calving difficulties on their farms. This study provides basic data on current calving practices and identifies areas for improvement

Received March 28, 2015.

Accepted November 11, 2015.

${ }^{1}$ Corresponding author: marianne.villettaz@gmail.com and potential targets for knowledge transfer efforts or research to clarify best management practices.

Key words: survey, calving practices, calving pen, cattle obstetrics

\section{INTRODUCTION}

Calving is a critically important event in every dairy animal's life as it is essential for the initiation of lactation and the production of replacement heifers. Recent research on calving has shown the effect of calving difficulty on the health, behavior, productivity, and welfare of dairy cows and calves during the pre- and postpartum periods (Schuenemann et al., 2011; Barrier et al., 2012, 2013).

The Canadian Dairy Code of Practice for the Care and Handling of Dairy Cattle (DFC-NFACC, 2009) contains both requirements and recommendations for best practices that have been established based on scientific evidence and industry-accepted standards. The Code of Practice requires that calving must take place in an area that provides comfort, insulation, warmth, dryness, and traction to prepartum cows. The recommended best practices are to ensure each cow has access to either an individual calving pen or adequate space in a group pen, equipped with a feeder and a source of water. It also recommends that farmers monitor and manage group pens to prevent aggressive behavior between cows. This Code of Practice is important for improving animal welfare, and information on the adoption of the code's standards by the dairy industry in Canada has been reported recently (Vasseur et al., 2015).

The USDA National Animal Health Monitoring System (NAHMS) Dairy 2007 study found that 60.5\% of operations surveyed had general guidelines (not necessarily a standard operating protocol) on when to intervene during calving and that $91.9 \%$ of farms provided training on calving assistance to their workers (USDA, 2009). Only $70.1 \%$ of farms had a calving area 
separated from lactating cow housing, with $96.2 \%$ of those being group or individual calving pens (USDA, 2010a). The study also found that some tiestall and stanchion farms left their cows in their usual stalls for calving but did not quantify the use of this practice.

Such an extensive survey has not been done in Canada. A survey restricted to tiestall dairy farms in the province of Québec, conducted between 2005 and 2007 (Vasseur et al., 2010), found that $51.3 \%$ of farms used tiestalls as housing for calving. Considering the frequency of observation of cows close to calving, they found a median of 3 visits by producers during the day and 1 during the night. Vasseur et al. (2010) believed that these practices had a negative effect on calf welfare. They also found that only $8 \%$ of producers used cameras to monitor calving progress. A similar survey on calf management was conducted on 964 dairy farms in Ontario in 2011 (Ken Leslie, University of Guelph, Guelph, ON, Canada; personal communication) and found that only $31 \%$ of farms used individual maternity pens for calving, whereas $11.6 \%$ used group pens, $7.9 \%$ either tiestall or freestall areas, and $29.6 \%$ used pasture when appropriate. These studies suggest that many Canadian producers were not following the Code of Practice in at least some respects, but more recent and detailed data are needed to determine if practices have changed.

Unfortunately, the surveys done in Québec and Ontario provided limited information on management practices surrounding calving, other than type of calving area. In addition, the previous Canadian surveys did not provide detailed information on the types of calving areas being used, bedding types, cleanliness in maternity areas, or on the timing and reason for providing assistance during calving. The NAHMS 2007 survey does provide some information on calving area bedding management for group and individual calving pens (USDA, 2010b). This type of information is essential to assess producers' adoption of science-based best practices and the potential lack of knowledge, effectiveness of knowledge transfer to the industry, or producers' attitudes toward the adoption of certain practices. Consequently, the objective of this study was to collect information on the prevalence of several calving management practices used in the Canadian dairy industry in terms of housing and calving monitoring and assistance.

\section{MATERIALS AND METHODS}

The research ethics boards and institutional animal care committees of the following institutions approved all procedures used in this study based on the guidelines of the Canadian Council for Animal Care: University of
Guelph (Guelph, Ontario, Canada), Université Laval (Québec, Québec, Canada), and University of Calgary (Calgary, Alberta, Canada).

\section{Herd Selection and Description}

A total of 236 dairy farms from 3 Canadian provinces (Alberta, $\mathrm{n}=56$, Ontario, $\mathrm{n}=90$, and Québec, $\mathrm{n}=90$ ) were surveyed for this study. Freestall $(\mathrm{n}=136)$ and tiestall (TS: $n=100$ ) housing systems were visited. Among farms using freestall housing, milking was performed using automated milking systems (AMS: $\mathrm{n}=$ 24) or conventional parlors for milking (FS: $\mathrm{n}=112)$. The exact distribution of number of milking cows and the average milk production of the herds surveyed are shown in Table 1. Average milk production per farm was calculated based on the results of recorded milk production over the 3 previous years (2008-2011).

To be eligible to participate in the study, the herds needed to be enrolled in the regional dairy herd improvement programs (CanWest DHI in Alberta and Ontario; Valacta Inc. in Québec); have a minimum of 40 Holstein milking cows in production at the time of the on-farm assessment; have a minimum average milk production of $7,000 \mathrm{~kg} / \mathrm{cow}$ per year; and provide no outdoor access to their lactating animals. These selection criteria were used to ensure that the farms surveyed were representative of the Canadian dairy industry. Farms were also selected based on longevity of their cows, defined by the percentage of cows in third lactation and higher and the annual replacement rate (Vasseur et al., 2015). For purposes of another study, all the Alberta farms were participants in The Alberta Hoof Health Project. Participation was voluntary after an initial contact was made by the research team, through letters mailed (Ontario and Alberta) or phone calls made by their DHIA advisor (Québec). Following return of letters indicating producers' interest in participating in the study, they were interviewed by phone to determine their admissibility based on additional study inclusion criteria, including having used their current housing system for at least $1 \mathrm{yr}$ and milking twice a day (other than AMS farms). Data were collected between January 2011 and April 2012.

\section{Data Description and Collection Procedure}

Trained observers $(\mathrm{n}=6)$ completed the survey during a one-on-one interview with the producer, during a farm visit between January 2011 and April 2012. For each farm enrolled, 1 observer and 1 trained helper (n =9) visited the farm. A total of 19 questions concerning calving management practices, mainly covering the time of calving itself, were included as part of a larger questionnaire. The questions to investigate calving 
practices were yes/no, multiple choice, or semi-closed. Producers were also asked to specify the percentage of use (e.g., percentage of calvings occurring in a given type of calving area) or time (in minutes, hours, or days) to clarify their answers to some questions. The questions related to 3 main topics of calving management: calving area; calving monitoring and protocol; and calving difficulties and assistance.

The questions relating to calving area were themselves related to 3 main topics: calving area type, bedding usage, and cleaning of the calving area. A total of 7 options were given to the producers to select the type of calving area: individual calving pen, a specially adapted tiestall, group calving pen, tied in a calving pen, regular tiestall, regular freestall, or other. A specially adapted calving tiestall was defined as a modified tiestall that was wider and longer than the regular tiestalls on that particular farm that was used specifically for calving animals. When more than one type of calving area was used on the same farm, the percentage use for each of the selected options was detailed by the producers. Questions related to bedding and cleanliness explored the following: the number of calvings before the addition of bedding; the complete changing of bedding and washing of the calving area with soap or disinfectant; and the type and amount of bedding used. When dairy producers were asked how much bedding they used in their calving area, they were shown a ruler to help them better estimate the depth $(\mathrm{cm})$ of bedding covering the floor of the calving area. Other questions concerned the amount of time spent by the cows in the calving area.

The use of calving protocols and protocols on farms were also part of the questionnaire. Questions on the monitoring of calving and assistance provided, as well as whether difficult calvings were perceived to be a problem on their farm, using a 4-point scale from not a problem (1) to a major problem (4), were included. A difficult calving was defined to the producers as a dystotic calving or assisted with some degree of difficulty.

Four environment-based measures of the calving areas were taken: length and width of the areas, flooring type, presence of feeding space, and cleanliness. On farms with more than 1 area in which calvings sometimes occurred, up to 4 areas were assessed. Cleanliness of the calving areas was evaluated on a 3-point scale: clean, acceptable, and unacceptable. Classification of cleanliness was based on the coverage of manure soiling on the wall and floor of the calving area and bedding humidity and done using an example chart (Canadian Dairy Research Portal; https://www.dairyresearch.ca/ animal-comfort-tool.php). To be considered clean, an area had to have no manure soiling on its surface or walls and the bedding had to be clean and dry. An area classified as acceptable could have some manure soiling on the walls and surface but the majority of the area had to be dry and clean.

\section{Statistical Analysis}

The data were analyzed using Stata 11 (StataCorp LP, College Station, TX) statistical software. Descriptive statistics were used to estimate mean values, percentage, range, and confidence intervals for each question in the survey. The prevalence was determined by specific barn types and herd size for the following calving practices: the type of calving area used, the use of a camera for calving monitoring, having a calving protocol, keeping records of calving difficulties, recall-

Table 1. Characteristics of dairy farms enrolled in the study by herd size and barn type

\begin{tabular}{|c|c|c|c|c|c|c|c|c|c|c|c|}
\hline \multirow[b]{2}{*}{ Item } & \multirow{2}{*}{$\begin{array}{l}\text { No. of } \\
\text { farms }\end{array}$} & \multicolumn{5}{|c|}{ Number of milking cows } & \multicolumn{5}{|c|}{ Milk production (kg) } \\
\hline & & Minimum & $\mathrm{Q} 2^{1}$ & Median & $\mathrm{Q} 3^{1}$ & Maximum & Minimum & Q2 & Median & Q3 & Maximum \\
\hline$\leq$ Median $^{2}$ & 115 & 41 & 51 & 61 & 69 & 82 & 7,048 & 8,598 & 9,240 & 9,744 & 11,862 \\
\hline $\mathrm{AMS}^{3}$ & 13 & 48 & 62 & 67 & 72 & 82 & 8,121 & 8,967 & 9,565 & 10,061 & 10,586 \\
\hline Freestall & 17 & 44 & 54 & 68 & 72 & 81 & 7,630 & 8,379 & 9,517 & 10,120 & 10,579 \\
\hline Tiestall & 85 & 41 & 51 & 58 & 64 & 82 & 7,048 & 8,628 & 9,162 & 9,644 & 11,862 \\
\hline$>$ Median $^{4}$ & 114 & 83 & 103 & 131 & 182 & 504 & 7,375 & 8,949 & 9,487 & 10,152 & 11,941 \\
\hline AMS & 7 & 97 & 102 & 133 & 224 & 283 & 8,192 & 8,480 & 9,040 & 9,586 & 9,808 \\
\hline Freestall & 92 & 83 & 112 & 141 & 213 & 504 & 7,375 & 9,010 & 9,621 & 10,172 & 11,941 \\
\hline Tiestall & 15 & 83 & 87 & 89 & 98 & 115 & 8,413 & 8,656 & 9,009 & 10,030 & 11,202 \\
\hline Total $^{5}$ & 236 & 41 & 61 & 82 & 130 & 504 & 7,048 & 8,725 & 9,356 & 10,002 & 11,941 \\
\hline AMS & 24 & 48 & 64 & 73.5 & 111 & 283 & 8,121 & 8,828 & 9,389 & 9,808 & 10,586 \\
\hline Freestall & 112 & 44 & 96 & 130 & 172 & 504 & 7,375 & 8,931 & 9,517 & 10,172 & 11,941 \\
\hline Tiestall & 100 & 41 & 51 & 61 & 71 & 115 & 7,048 & 8,631 & 9,153 & 9,691 & 11,862 \\
\hline
\end{tabular}

${ }^{1} \mathrm{Q} 2=25$ th percentile; $\mathrm{Q} 3=75$ th percentile.

${ }^{2}$ Herd size less than or equal to the median herd size of 82 lactating cows.

${ }^{3} \mathrm{AMS}=$ automatic milking system.

${ }^{4}$ Herd size greater than the median herd size of lactating 82 cows.

${ }^{5}$ Data unavailable for 7 AMS and 3 freestall farms. 
ing calculated incidence of calving difficulty (based on producers' memory of the past year), and reasons for obstetrical intervention. Herd size was dichotomized as less than or equal to or greater than $(\leq$ vs. $>)$ the median number of lactating cows for all the farms visited (median $=82)$. Before statistical analysis, the answers to each question were examined to detect aberrant and missing results.

Simple logistic regression models were generated to assess the influence of barn type and herd size on keeping records of calving difficulties, the use of cameras for monitoring calving, the practice of assessing all cows for problems at calving and assisting all cows or all heifers at calving. Multinomial logistic regression was used to assess the association between herd size and barn type on main type of calving area used. Multinomial logistic regression was also used to assess the association between herd size, barn type, and type of calving area on the time of movement of cows to the calving area and the association between herd size, barn type, and record keeping on perceived level of calving problem on the farm. Barn type and herd size (dichotomized) were forced into all models, as they were the main predictors of interest. Interactions between these predictors were also investigated. The significance level to retain variables or their interaction terms was $\alpha=0.05$.

\section{RESULTS}

\section{Characteristics of Farms Enrolled}

The characteristics of farms per housing type for milking cows, and type of barn are presented in Table 1. The number of milking cows was unavailable for 4 of the 24 AMS farms and for 3 of the 112 FS farms. The average 305-d milk yield was unavailable for 7 AMS and 3 FS farms. Overall, FS farms had a greater median number of cows and average milk production.

\section{Calving Area Characteristics}

Producers were asked where their cows calved, based on their memory of the last $365 \mathrm{~d}$ of calvings. The most commonly used types of calving areas were group calving pens in FS farms, individual calving pens in AMS farms, and tiestalls in TS farms (Table 2). Overall, the most common type was group calving pens. Tiestalls used for calving included regular stalls and those that were specially adapted for calving. The "other" type category also included bedded pack, dry lot, and pasture. When 2 types of calving areas were used equally, these farms were classified as using "50/50" type calving areas. More than one type of calving area was used on $47 \%$ of farms, and the percentage of use for each of the selected options was detailed by the producers based on their memory of a complete year of calving. Regular freestall was the location where the least number of calvings occurred, whereas group pen was where most of the calvings happened (Table 3). Larger farms had significantly greater odds of using group pens than individual calving pens. The odds of using tiestalls for calving compared with individual calving pens was significantly greater on TS farms compared with AMS and FS farms (Table 4).

Straw was used as bedding in the calving area on $75 \%$ of the farms visited (95\% CI: $69.0-80.4$ ), whereas a mix of wood shavings and straw was used on $8.5 \%$ of farms (95\% CI: 5.3-12.8), wood shavings alone in $7.2 \%$ (95\% CI: $4.3-11.3$ ), sawdust in $6.4 \%$ (95\% CI: $3.6-10.3)$, and sand alone by only $1.3 \%$ of producers (95\% CI: 0.3-3.7). The other types of bedding used were chopped hay, dried manure, peat moss, and a variety of mixed bedding types.

The average reported bedding depth across bedding type, barn type and herd size was $16 \mathrm{~cm}(\mathrm{n}=223 ; 95 \%$ CI: 14.5-17.6). Depending on the type of bedding, the highest average amount of bedding was seen with sand $(\mathrm{n}=2$; mean $=40 \mathrm{~cm}$; range $30-50 \mathrm{~cm})$ and lowest with wood shavings $(\mathrm{n}=15$; mean $=10.9 \mathrm{~cm} ; 95 \% \mathrm{CI}$ : 5.5-16.2). Straw bedding users covered their calving area with an average of $16.6 \mathrm{~cm}$ of straw $(\mathrm{n}=171 ; 95 \%$ CI: $14.8-18.3)$.

In terms of adding bedding and cleaning the calving area, bedding was added, on average, every 2 calvings ( $\mathrm{n}=228 ; 95 \% \mathrm{CI}: 1.4-2.2)$ and completely changed every 15 calvings $(\mathrm{n}=206 ; 95 \%$ CI: $11.8-18.0)$. Only $8 \%$ of the producers surveyed washed their calving area and this was done, on average, every 61 calvings (n $=17 ; 95 \%$ CI: 10.6-111.6). Disinfection occurred on $12.3 \%$ of the farms visited and this was done, on average, every 34 calvings ( $\mathrm{n}=27 ; 95 \%$ CI: 18.7-48.7). Bedding management differed by type of calving area; tiestall users usually changed the bedding completely between each calving (Table 6).

A total of 385 calving areas were visually evaluated on 194 farms for the presence of a working source of drinking water and feeding space, to assess flooring type, and document cleanliness. A minimum of 1 and maximum of 4 calving areas were evaluated on each farm $($ mean $=1.9 ; 95 \%$ CI: $1.7-2.0)$. Within the 220 farms evaluated, 8 used their regular freestall or tiestall as a calving area. In total, $48.6 \%(\mathrm{n}=187 ; 95 \% \mathrm{CI}$ : $37.8-48.2)$ of the areas evaluated were individual calving pens, 30.1\% ( $\mathrm{n}=116 ; 95 \%$ CI: 25.4-35.0) were group pens, $10.1 \%(\mathrm{n}=39 ; 95 \% \mathrm{CI}: 8.2-15.0)$ were adapted calving tiestalls, and $11.2 \%(\mathrm{n}=43 ; 95 \%$ CI: 2.8-7.4) were calving tiestalls.

Almost every calving area evaluated was equipped with a working source of drinking water $(97 \%$; $95 \%$ CI: 
94.9-98.7) and a feeding area (97\%; 95\% CI: 94.2-98.3). Concrete was the most commonly used type of flooring in calving areas (34\%; 95\% CI: 29.2-39.3) followed by bedded pack, with or without a concrete feeding alley (23\%; 95\% CI: $18.8-27.8)$, and rubber mats (19\%; $95 \%$ CI: 14.7-23.0). Other main types of flooring recorded were geotextile mattresses (12\%; 95\% CI: 8.7-15.7), soil (7\%; 95\% CI: 4.6-10.2), and sand (4\%; 95\% CI: $2.2-6.5)$. The most common flooring in adapted calving tiestalls and regular tiestalls used for calving were geotextile mattresses (41\%; 95\% CI: 28.6-55.1) and rubber mats (43\%; 95\% CI: 30.2-56.8), respectively. Concrete flooring was used most commonly in the other calving area types.

When cleanliness of the calving areas was evaluated, in total, $32 \%$ (95\% CI: 26.7-36.6) of the 356 areas evaluated were classified as clean, $46 \%$ (95\% CI: 40.5-51.1) as acceptable, and $23 \%$ (95\% CI: $18.5-27.5)$ as unacceptable.

Table 5 summarizes the length, width, and calculated surface of the calving areas measured on 220 farms (n $=385$ calving areas). As expected, group calving pens had the longest dimensions, followed by individual calving pens and adapted tiestalls. The exact shapes of the calving areas measured were not noted by observers, but the surface area available to the cows during calving was approximated by multiplying the length and width of the area measured. The average area of group calving pens was 7 times larger than the average area of individual pens (140 vs. $20 \mathrm{~m}^{2}$ ). Specially designed tiestalls provided on average $1 \mathrm{~m}^{2}$ more space to the cow calving compared with regular tiestalls (3.3 vs. 2.3 $\mathrm{m}^{2}$ ).

\section{Use of Calving Area}

Producers were asked when the cows and heifers were brought to the calving area ( $\mathrm{n}=216$ responses). Overall, $42 \%$ (95\% CI: 35.0-48.5) of the producers said they brought their cows at the start of the prepartum period, 3 wk before their due date, and 25\% (95\% CI: 19.4-31.3) said they moved the cows when the first signs of calving were detected. First signs of calving could be anything from restlessness and udder fill to bloody mucus, amniotic sac, or part of the calf emerging from the vagina. Producers using individual calving pens most often brought their cows into the calving pen when the first signs of calving were detected $(47.9 \%$; 95\% CI: 35.9-60.1), whereas group pen $(58.0 \%$; 95\% CI: 46.5-68.9) and tiestall (55.8\%; 95\% CI: 39.9-70.9) users most often used the start of the prepartum period to determine when to bring cows to the calving area. In fact, producers using a group pen or tiestall were more likely to bring their cows to the calving area either at 
the start of the dry-off period or the close-up period rather than when the first signs of calving were detected, compared with individual pen users (Table 4).

When asked the same question in terms of hours or days before calving, the mean time cows spent in the calving area was $14.5 \mathrm{~d}$, ranging from $1 \mathrm{~h}$ to 70 $\mathrm{d}(\mathrm{n}=204 ; 95 \%$ CI: $12.3-16.7 \mathrm{~d})$. This varied greatly depending on the type of calving area. After calving, the average time cows spent in the calving area was $47.3 \mathrm{~h}$, ranging from $<1 \mathrm{~h}$ to $15 \mathrm{~d}(\mathrm{n}=211 ; 95 \% \mathrm{CI}$ : 38.6-56.0 h).

Overall, cows calving in group calving pens were provided deeper bedding but the least frequent complete change of bedding. Tiestalls used for calving were found to be generally cleaner where cows spent more time before and after calving compared with individual and group pens (Table 6).

\section{Calving Monitoring}

The average reported number of times the calving area was checked during the day (i.e., between the morning and the afternoon milking or chores) was 6.3 (95\% CI: 5.6-7.0). The average reported number of times the calving area was checked during the night (i.e., between the afternoon and the morning milking or chores) was 1.7 (95\% CI: 1.5-1.8). These observations included any live observations by an individual and those done using a camera.

Cameras were used to monitor cows during calving on $18 \%$ of farms (95\% CI: 13.5-23.7). The AMS farms used cameras significantly more often $(38 \% ; 95 \%$ CI: 18.8-59.4) compared with FS farms (17\%; 95\% CI: 10.5-25.2), and TS farms (15\%; 95\% CI: 8.6-23.5), but herd size did not significantly influence the use of cameras (Table 7).

\section{Calving Protocol}

Sixteen of the 236 farms surveyed $(7 \% ; 95 \%$ CI: 3.9-10.8) had written protocols for calving. More specifically, $11 \%$ (95\% CI: $4.8-16.2$ ) of farms over the median size had calving protocols, compared with only 3\% (95\% CI: $-0.3-5.6)$ of smaller farms. Within the 16 farms that had a protocol, $50 \%$ had developed their protocol in consultation with a veterinarian. When investigating the content of the protocols, $81 \%(95 \%$ CI: 54.4-96.0) of them included both a method for calf pulling and instructions for when and how to assist cows during a difficult calving. The use of lubricant and gloves was specified in $69 \%$ (95\% CI: 41.3-89.0) of the protocols. Six producers (37.5\%; 95\% CI: 15.2-64.6) had other items in their calving protocol, including treatment for the cows after calving, calf separation method, colostrum testing, and colostrum feeding.

\section{Calving Difficulties and Assistance}

Most producers used vaginal palpation to detect a problem during calving for all their animals when the amniotic sac (water bag) had broken and calving had not progressed or when the cow was straining without progress for "too long." The average waiting time to palpate was $81 \mathrm{~min}$ after the amniotic sac had broken or 89 min after the cow was first seen straining, with a waiting time ranging from $5 \mathrm{~min}$ to $11 \mathrm{~h}$ (Table 8). A total of $15.7 \%$ (95\% CI: 11.3-21.0) of respondents always performed vaginal examinations on their cows at calving (on all animals); this practice was significantly more common on TS farms compared with FS farms (Tables 7 and 8).

Producers were asked when they assisted their cows at calving with 7 choices of answers. Table 9 presents the distribution of the reasons for assistance globally, by farm type, and by herd size. Interestingly, 26.7\% (95\% CI: 21.2-32.8) of producers answered they assisted all their cows during calving by pulling the calves, as a systematic procedure. A significant interaction was found between farm type and herd size for the odds of this practice, leading to the practice being more frequent on the larger TS farms than any other combination of

Table 3. Proportion estimated by the producers of calvings on 236 farms that occur in each type of calving area

\begin{tabular}{|c|c|c|c|c|}
\hline \multirow[b]{2}{*}{ Type of calving area } & \multirow{2}{*}{$\begin{array}{l}\text { No. of farms with } \\
\text { this type of } \\
\text { calving area }\end{array}$} & \multicolumn{3}{|c|}{$\begin{array}{l}\text { Calvings that took place } \\
\text { in this type of area }(\%)^{1}\end{array}$} \\
\hline & & Mean & Range & $95 \% \mathrm{CI}$ \\
\hline Individual pen & 111 & 67.4 & $1-100$ & $61.0-73.8$ \\
\hline Group calving pen & 102 & 85.2 & $5-100$ & $73.2-97.2$ \\
\hline Specially adapted tiestall & 25 & 81.7 & $2-100$ & $75.7-87.6$ \\
\hline Regular tiestall & 58 & 71.6 & $1-100$ & $61.6-81.7$ \\
\hline Regular freestall & 25 & 18.2 & $1-100$ & $7.0-29.3$ \\
\hline Other & 31 & 33.1 & $1-100$ & $19.6-46.6$ \\
\hline
\end{tabular}


Table 4. Multivariable multinomial logistic regression models investigating the effect of farm type, herd size, and, in some cases, type of calving area used or keeping written records of difficult calvings on the odds of using a certain type of calving area, of moving cows at a specific moment to the calving area, and of producers classifying their farm as having a different level of calving difficulty

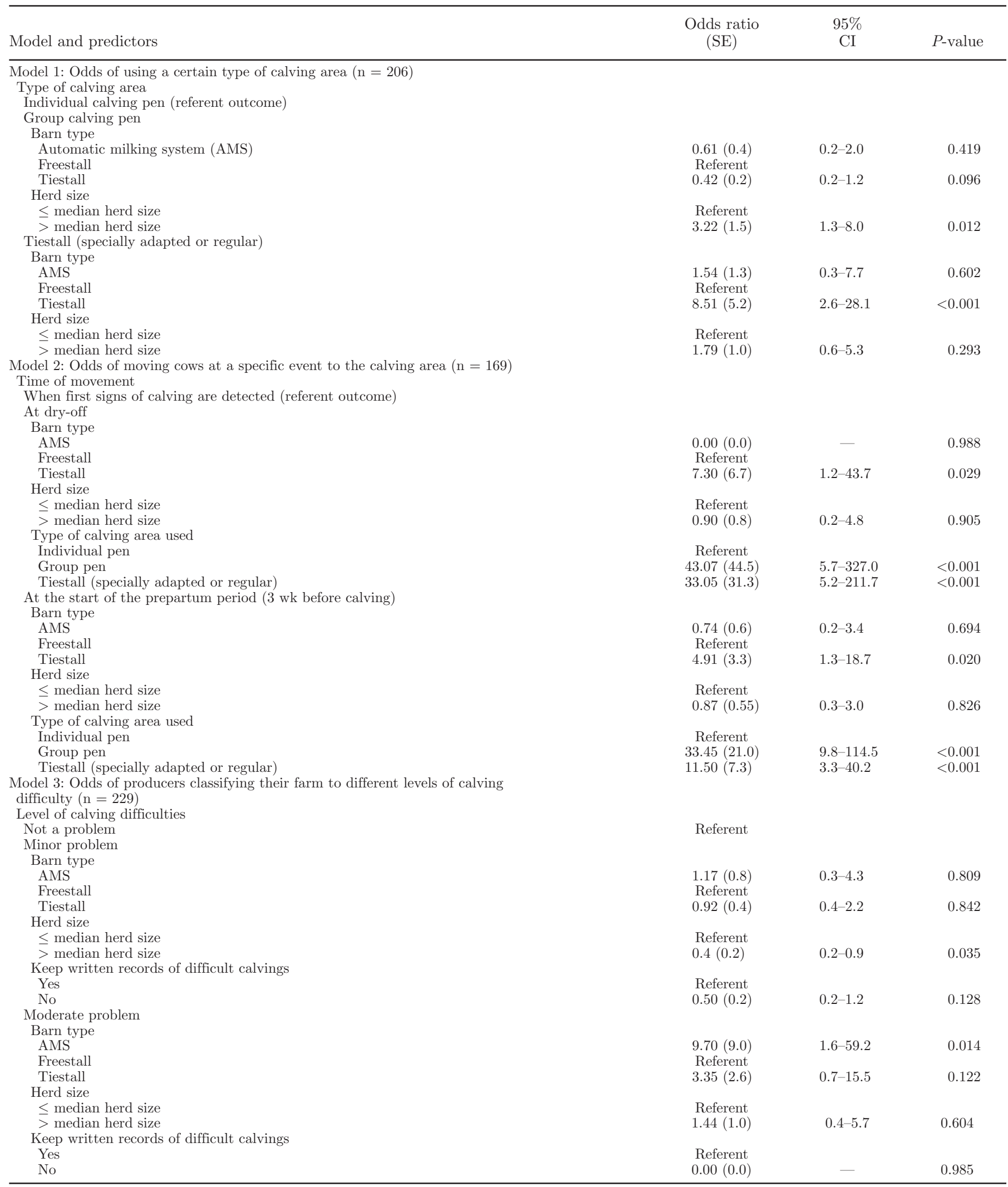


Table 5. Sizes of pens and stalls used for calving on 220 farms

\begin{tabular}{|c|c|c|c|c|}
\hline \multirow[b]{2}{*}{ Item } & \multirow{2}{*}{$\begin{array}{c}\text { No. of areas } \\
\text { measured }\end{array}$} & \multicolumn{3}{|c|}{ Measure $(\mathrm{cm})$} \\
\hline & & Mean & Range & $95 \% \mathrm{CI}$ \\
\hline Individual calving pen & 187 & & & \\
\hline Length & & 492.8 & $275-1,205$ & $468.4-517.2$ \\
\hline Width & & 410.5 & $240-855$ & $396.0-425.0$ \\
\hline Area $\left(\mathrm{m}^{2}\right)$ & & 20.5 & $8.7-82.1$ & $19.1-21.9$ \\
\hline Group calving pen & 116 & & & \\
\hline Length & & $1,330.9$ & $331-9,040$ & $1,111.1-1,550.7$ \\
\hline Width & & 821.5 & $230-5,640$ & $701.1-941.9$ \\
\hline Area $\left(\mathrm{m}^{2}\right)$ & & 140.0 & $11.1-1,314.1$ & $96.3-183.7$ \\
\hline Specially adapted tiestall & 39 & & & \\
\hline Length & & 212.3 & $180-345$ & $198.3-226.3$ \\
\hline Width & & 158.6 & $127-286$ & $147.3-19.9$ \\
\hline Area $\left(\mathrm{m}^{2}\right)$ & & 3.3 & $2.5-9.9$ & $3.0-4.0$ \\
\hline Regular tiestall & 43 & & & \\
\hline Length & & 179.7 & $157-223$ & $203.3-359.6$ \\
\hline Width & & 126.9 & $104-147$ & $156.9-293.7$ \\
\hline Area $\left(\mathrm{m}^{2}\right)$ & & 2.3 & $1.8-3.3$ & $2.2-2.4$ \\
\hline
\end{tabular}

type and size of farms [odds ratio $(\mathbf{O R})=15.1$ when compared with small AMS farms $(P=0.005 ; 95 \%$ CI: $2.3-100.3) ; \mathrm{OR}=6.6$ when compared with small FS farms $(P=0.017 ; 95 \%$ CI: $1.4-31.1)$; Table 7$]$. The farms that were the least likely to assist all their cows were the larger FS farms $[\mathrm{OR}=0.16$ when compared with large AMS farms $(P=0.029 ; 95 \%$ CI: 0.3-0.83); $\mathrm{OR}=0.04$ when compared with large TS farms $(P$ $<0.001 ; 95 \%$ CI: 0.01-0.17); Table 7]. The remaining $73 \%$ (95\% CI: $67.2-78.8)$ of producers answered that they assisted a cow only after checking her and finding a problem. A total of $38 \%$ (95\% CI: 17.1-27.8) of producers surveyed gave assistance every time a heifer (primiparous cow) was calving. The odds of assisting all primiparous animals were significantly greater in AMS farms compared with FS farms but not compared with TS farms (Table 7). Other cited reasons for providing assistance at calving were a large calf, the cow was experiencing milk fever (i.e., hypocalcemia), and the calving was not progressing.

When assisting a cow with a difficult calving, producers most frequently used a calving jack $(39 \% ; 95 \%$ CI: $32.8-45.6$ ), followed by ropes (31\%; $95 \%$ CI: $24.6-36.8)$ or chains $(25 \%$; $95 \%$ CI: 19.1-30.5) without a jack, and chains with a bar $(4 \% ; 95 \%$ CI: $2.1-7.8)$. Only $2 \%(95 \%$ CI: $0.5-4.3)$ of producers surveyed generally called a veterinarian to assist during difficult calvings.

Management practices investigated also included keeping records of calving difficulties and the proportion of difficult calvings occurring on each farm visited $(\mathrm{n}=230)$. Producers were asked to recall how many animals calved during the past year and how many had a difficult calving. In this case, difficult calving was defined to the producers as dystotic calving or assisted with some degree of difficulty. Farms that kept records of calving difficulties reported an estimated calving difficulty incidence of $8 \%$ (95\% CI: 7.5-9.1), whereas farms that did not keep records reported an incidence of $7 \%$ (95\% CI: 4.6-8.3; Table 10). Producers were asked if they thought that calving difficulty was a problem on their farm. Overall, the majority of producers stated they had a minor problem with calving difficulty on their farm (Table 11). The distribution of the calculated percentage of cows experiencing calving difficulty as recalled by perceived level of calving difficulty and proportion of farms keeping records in each of those categories is shown in Table 11. Producers with larger herds were less likely to classify themselves as having a minor problem than no problem with calving difficulties compared with producers with smaller herds (Tables 4 and 11). However, there was no significant relationship between herd size and an owner stating they had a moderate problem versus no problem with calving difficulties. Producers of AMS farms were also significantly more likely than FS farms to classify themselves has having a moderate problem with calving difficulties compared with no problem (Table 4).

\section{DISCUSSION}

This survey gathered information on current practices related to calving management on different types of dairy farms in Canada. It has allowed us to estimate the prevalence of some known practices, such as the use of tiestalls as calving areas, and has uncovered the prevalence of practices for which very little information is available, including systematic assistance to all cows calving. The use of tiestalls during calving and systematic assistance are 2 practices that are generally considered to be potential risk factors for welfare, but 


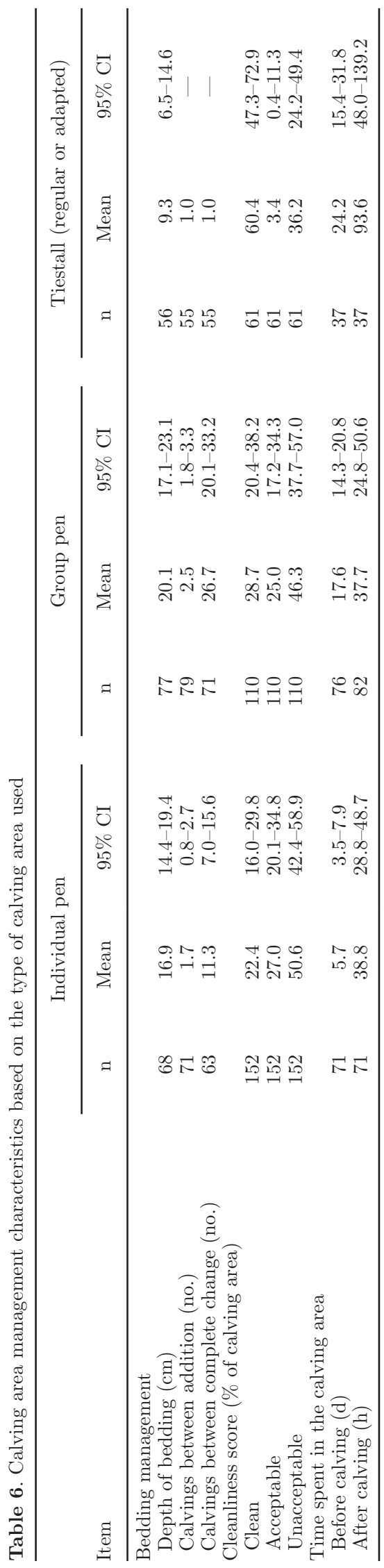

very little research has been published on the subject (Vasseur et al., 2010; Fishwick, 2011).

Almost two-thirds of farms used a dedicated area for calving, with almost equal numbers of farms using an individual pen and a group pen. Not surprisingly, larger farms were more likely to use group pens than individual pens. These results parallel those from the United States (USDA, 2010a) but differ from a survey conducted in Ontario, which found that $31 \%$ of producers used individual pens and $12 \%$ used group pens (Ken Leslie, University of Guelph, Guelph, ON, Canada; personal communication). Currently, the Canadian Dairy Code of Practice does not specifically require or recommend the use of one particular type of calving pen (DFC-NFACC, 2009). It is unclear whether individual or group calving pens should be recommended to producers; both types seem to be appropriate as long as they accommodate the behavioral needs of the animals, avoid crowding, and provide a clean environment (Cook and Nordlund, 2004). Good management of the space available per cow $\left(11 \mathrm{~m}^{2}\right.$ of lying area with clean fresh bedding added daily) in group maternity areas should avoid aggressive behavior between cows and toward newborn calves and address cleanliness issues.

About half of the tiestall farms purposely used a tiestall for calving, which was also found by Vasseur et al. (2010). However, a smaller number of freestall and AMS farms also used a tiestall for calving in this survey. This could be either a normal tiestall or one designed specifically for animals during calving (usually wider and longer than normal tiestalls). For cows usually kept in tiestalls, the use of this type of calving area could minimize any negative effects that could be caused by the change of environment (Mee, 2004) but it reduces the freedom of movement that might be greatly needed by cows as their activity increases significantly before parturition. Some freestall farms also used tiestalls with animals that may not be used to being tied, potentially leading to further negative welfare for those cows. Interestingly, $15 \%$ of the farms with alternative areas for calving still preferred to use a tiestall as their main calving area for the entire calving process. The prevalence of tiestall usage for calving is concerning, as Vasseur et al. (2010) suggested that the use of tiestalls for the calving area was a risk factor for poorer calf welfare and reduced cleanliness and dam comfort during calving. The exact impact of this practice on the behavior of cows and calving performance is unknown, but it seems reasonable that the mobility of cows and potentially their ability to find a comfortable position to expulse the fetus could be negatively affected by tethering (Vasseur et al., 2010). Knowing that cows can be very restless before and during parturition and that stress around calving can increase the risk of dystocia 
Table 7. Multivariable logistic regression models investigating the effect of barn types and herd size on the odds of using a camera to monitor calvings, always vaginally palpate cows at calving, routinely assist all calvings, and routinely assist all primiparous cows only at calving



(Mee, 2004), an investigation into the effect of using tiestalls and adapted tiestalls as calving areas would be beneficial for the welfare of the animals and producers.

In the current study, only $10.6 \%$ producers used regular freestalls as a calving environment. Only 4 $(1.7 \%)$ of the farms surveyed had $50 \%$ or more of their cows calving in regular freestalls, which is very different from the results of a Norwegian study that found most dairy farms using this practice (Kjæstad and Simensen, 2001). The use of freestall housing for calving is not encouraged because being born in a loose housing pen has been found to increase the risk of diarrhea in calves

Table 8. Reasons for vaginal examination by palpation at calving, and timing to assess potential calving difficulties $(\mathrm{n}=235)$

\begin{tabular}{|c|c|c|c|c|c|}
\hline \multirow[b]{2}{*}{ Reason for vaginal examination } & \multirow{2}{*}{$\begin{array}{c}\text { Farms that } \\
\text { answered } \\
\text { yes }(\%)\end{array}$} & \multicolumn{4}{|c|}{ Timing of the examination $(\min )^{1}$} \\
\hline & & $\begin{array}{c}\text { No. of } \\
\text { answers }\end{array}$ & Mean & Range & $95 \% \mathrm{CI}$ \\
\hline I always vaginally check (palpate) the cow at all calvings & 15.7 & - & - & - & - \\
\hline When the water bag has broken and the calving has not progressed ${ }^{2}$ & 61.3 & 118 & 81 & $5-360$ & $69.0-93.8$ \\
\hline When the cow is straining without progress for too long ${ }^{3}$ & 64.3 & 125 & 89 & $5-660$ & $74.1-104.3$ \\
\hline When the calf's feet have been visible for too long ${ }^{3}$ & 52.3 & 104 & 57 & $5-360$ & $47.4-66.2$ \\
\hline Suspect malpresentation & 48.5 & - & - & - & - \\
\hline
\end{tabular}

${ }^{1}$ Timing of the examination since the water bag broke, first sight of the cow straining or the calf's feet.

${ }^{2}$ Water bag defined as the allantochorion membranes/amniotic sac.

${ }^{3}$ Time zero was defined as the first time producers had seen the cow straining or the calf's feet. 
younger than $15 \mathrm{~d}$ by 4.6 times and by 2.5 times in calves up to $90 \mathrm{~d}$ of age compared with calves born in maternity pens (Curtis et al., 1988).

Specially designed tiestalls provided on average 1 $\mathrm{m}^{2}$ more area to the calving cow than normal tiestalls by being generally slightly longer and wider. Unfortunately, producers using group calving pens were not asked the average or maximum number of cows that might have been housed at the same time in the group calving pens. It was therefore impossible to calculate the average stocking density or space available per cow in group calving pens to compare them to the industry recommendation of a maximum of $100 \%$ stall-based stocking density and a minimum of $11 \mathrm{~m}^{2}$ (120 square feet) of lying area per cow (Cook and Nordlund, 2004). The average area of the individual calving pens was $20.5 \mathrm{~m}^{2}$, and only $6 \%$ of these pens provided less than the recommended $11 \mathrm{~m}^{2}$.

It has been recommended that cows spend 1 or 2 $\mathrm{d}$ before calving in the calving area to allow them to fulfill their natural isolation-seeking behavior without compromising the cleanliness and management of the calving area (Mee, 2004). Also, it is important to note that field observations have shown that cows spending $3 \mathrm{~d}$ or more in the maternity pen had an elevated risk of ketosis, displaced abomasum, and elevated blood nonesterified fatty acid concentrations (Cook and Nordlund, 2004). Most of the farms surveyed in this study brought their periparturient animals to the calving area a minimum of $3 \mathrm{wk}$ before the expected calving date. This practice was significantly different between farm types, with tiestall and group calving pen users more commonly bringing their cows a minimum of 3 wk before calving compared with those using individual calving pens, who usually brought their cows to these pens at the visible onset of calving. This represents one potential advantage of using tiestalls as a calving area; they might be easier to keep clean compared with individual or group calving pens due to their smaller size, and therefore avoid the inconvenience of having cows remain longer in the calving environment. Also, recent findings suggest that moving cows during the late part of stage I of labor leads to longer stage II labor (delivery), increased need for assistance, and increased dystocia rates and stillbirth rates (Carrier, 2007; Proudfoot et al., 2013).

The use of bedding in the calving area is the main means to provide comfort, insulation, warmth, dryness, and traction, as required by the Canadian Code of Practice (DFC-NFACC, 2009). Straw was used by $75 \%$ of producers as bedding in their calving area, at an average depth of $17 \mathrm{~cm}$. Cleanliness of the calving area is also of major importance for the comfort and safety of the animals. Removal of old bedding in the 
Table 10. Record keeping and reported proportion of difficult calvings in 236 herds in Canada

\begin{tabular}{|c|c|c|c|c|c|}
\hline \multirow[b]{2}{*}{ Item } & \multirow{2}{*}{$\begin{array}{l}\text { Keeping records of } \\
\text { calving difficulties (\%) }\end{array}$} & \multirow[b]{2}{*}{$95 \% \mathrm{CI}$} & \multicolumn{3}{|c|}{$\begin{array}{l}\text { Calculated incidence of } \\
\text { calving difficulty }(\%)\end{array}$} \\
\hline & & & Mean & Range & $95 \% \mathrm{CI}$ \\
\hline \multicolumn{6}{|l|}{ Barn type } \\
\hline $\mathrm{AMS}^{1}$ & 91.7 & $80.3-100$ & 8.6 & $0.5-30.0$ & $6.1-11.2$ \\
\hline Freestall & 90.2 & $84.6-95.7$ & 7.9 & $0.6-29.2$ & $6.8-9.1$ \\
\hline Tiestall & 90.0 & $84.1-96.0$ & 8.2 & $0-33.3$ & $7.1-9.3$ \\
\hline \multicolumn{6}{|l|}{ Herd size } \\
\hline$\leq$ median herd size & 92.2 & $85.7-96.4$ & 9.1 & $0-33.3$ & $8.0-10.2$ \\
\hline$\overline{>}$ median herd size & 87.7 & $80.3-93.1$ & 7.1 & $0-30.0$ & $6.1-8.2$ \\
\hline Total & 90.3 & $85.7-93.7$ & 8.1 & $0-33.3$ & $7.3-8.9$ \\
\hline
\end{tabular}

${ }^{1} \mathrm{AMS}=$ automated milking system.

calving area has been found to reduce the incidence of calf diarrhea and Johne's disease (Frank and Kaneene, 1993; McKenna et al., 2006). Of the farms surveyed, very few producers washed their calving area with soap or disinfected the area. On the other hand, bedding was added to the calving area by most producers after every second calving and removed completely, on average, after every 15 calvings. These cleaning and bedding management practices are not optimal to avoid transmission of disease, but $78 \%$ of the calving areas evaluated had an acceptable or higher cleanliness score.

Very few farms $(7 \%)$ had a written calving protocol, which is almost 9 times lower than in the United States (USDA, 2010a). This difference is unlikely to be related to the difference in size between the average Canadian and American dairy operation surveyed because $62 \%$ of the farms in the NAHMS survey that had fewer than 100 milking cows also had some sort of calving protocol (USDA, 2010a). The observed difference could be explained partly by the number and type of workers on the farm. The current survey did not collect specific information on the farms employees but the Canadian dairy industry is still mainly constituted of owner/ operator dairies with very few, if any, employees that are not direct family. This may lead farmers to underestimate the importance of calving protocols and could explain the small number of farms with such a protocol.

Monitoring of cows during the prepartum period is important to detect signs of the onset of calving.
Monitoring cows after the onset of parturition is also important for detecting a lack of progress or signs of other problems. Monitoring can be done in-person or remotely with the use of cameras. In the current survey, $18 \%$ of farms used cameras to monitor calving, which is higher than that recorded by Vasseur et al. (2010) in tiestall farms in Québec. It has been recommended that after detecting the onset of calving, cows should be monitored approximately every 3 to $6 \mathrm{~h}$ to detect the onset of the second stage of labor (appearance of the chorio-allantoic membrane and complete expulsion of the calf; Mee, 2004). According to previous studies, cows in active labor should show evident progress every 15 min during a normal calving (Schuenemann et al., 2011). If progress is normal, discrete monitoring is recommended every $30 \mathrm{~min}$ or continuously if possible (Mee, 2008a). Producers interviewed for this survey monitored calving a median of 5 times during the day but only once during the night. The AMS farms were more likely to use cameras to do some of this monitoring. Because the question did not distinguish between monitoring of cows before or during calving, it is difficult to accurately assess the use of best management practices.

It has been recommended that all cows be examined during stage II of labor to check the position, vigor, and size of the calf, as well as the degree of dilation of the vagina and vulva (Mee, 2004). This management practice was followed by $16 \%$ of the producers

Table 11. Perception of the magnitude of the problem of calving difficulty by 236 Canadian dairy producers and their record keeping and reported incidence of difficult calvings

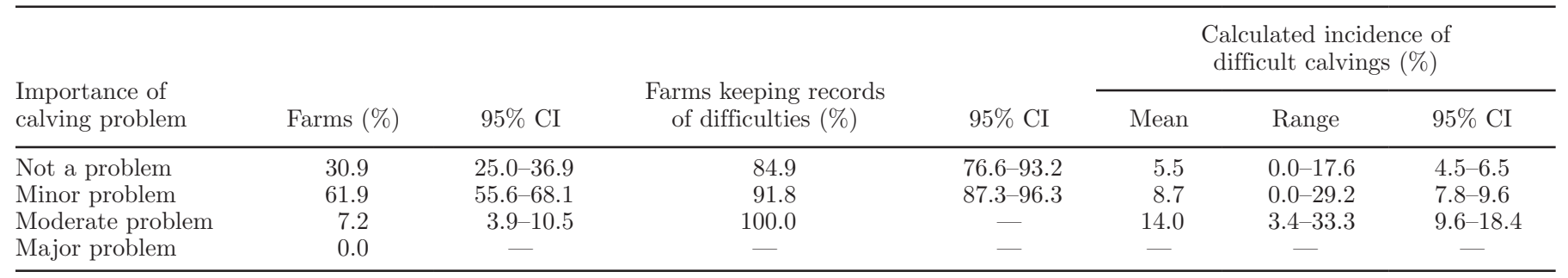


surveyed in the current study and was most frequently done on tiestall farms. The remaining producers vaginally checked their cows and heifers when no significant progress was made after a certain amount of time, varying from 5 min to $10 \mathrm{~h}$. Mee (2004) recommends giving assistance to cows approximately $2 \mathrm{~h}$ after the onset of stage 2 labor. Schuenemann et al. (2011) found that assisting $70 \mathrm{~min}$ following the appearance of the amniotic sac or $65 \mathrm{~min}$ after the appearance of feet reduced the incidence of stillbirth when combined with adequate obstetrical examination and assistance. The same authors stated that earlier intervention has the potential to prevent stillbirth as well as dam injury in some cases. In the present study, $27 \%$ of producers assisted all cows at calving. This practice was more prevalent than expected and more common on larger farms. There is very little information available on the prevalence of this practice on dairy farms in other parts of the world, or on its health and welfare effects on cows and calves. Unfortunately, neither the exact timing nor the protocol used for systematic assistance was recorded in this survey.

When asked about the importance of calving difficulties as a problem on their farms, no producers answered that they had a major problem and most stated they had a minor problem or no problem at all. When they were asked about the number of cows that experienced calving difficulty on their farms, producers answered that up to one-third of their animals experienced some form of dystocia. Interestingly, more producers that did not keep written records of difficult calvings judged that calving difficulties were not a problem on their farms compared with the ones that did but this finding was not statistically significant. Also, all producers who stated that they had a moderate problem of calving difficulties did keep written records. This incidence of calving difficulties (33\%) could be considered a significant problem because the incidence reported in the literature for American Holsteins was $13.7 \%$ for cows and $22.6 \%$ for heifers (Gevrekci et al., 2006; Mee, 2008b). Calving difficulties were not viewed as an important problem by producers, perhaps because they are not aware of the impacts and cost of this problem. The costs of calving difficulties, especially slight difficulties, are not as easily measured and are not as direct as other problems such as lameness or poor reproduction, but difficult calvings have been found to increase the risks of metritis and culling and to reduce fertility and milk production in the cows (Benzaquen et al., 2007; Bicalho et al., 2007; McGuirk et al., 2007). Difficult calvings have also been found to increase risks of mortality and morbidity in newborn calves (Berglund et al., 2003; Lombard et al., 2007). Overall costs of a very difficult calving have been estimated to be up to about $\$ 800$ per case (McGuirk et al., 2007).

Participation in this study was voluntary. The proportion of farms for each type was predetermined by the researchers to be representative of the prevalence of each type in their respective provinces and covered the main housing and milking types used in Canada. This type of enrollment in the study could have led to some selection bias because it was not a truly random selection process, but the final sample of farms visited was a reasonable representation of the current dairy industry in Canada based on average milk production, herd size, and breed. The average milk production for the farms enrolled in this study was $9,356 \mathrm{~kg}$ of milk per year, which was slightly lower than the 2011 Canadian average of Holstein herds with DHIA supervision records $(9,975 \mathrm{~kg})$ (AAFC, 2012). The average herd size of farms enrolled in this study was equal to the Canadian average according to statistics published by the Canadian dairy industry (AAFC, 2012; 82 vs. 82.3 milking cows, respectively).

For some of the questions, misclassification bias might have occurred in this study due to the social desirability of some practices, in the sense that producers might modify their answers to be consistent with the greater industry's code of practice. However, in the present case, this type of misclassification is unlikely as the recommended best practices for calving management are vague in the Code of Practice and therefore the potential "ideal" response to the questions would not be obvious. Overall, most producers followed the recommended best practices from the Dairy Code of Practice, although these are broad and not prescribed in detail.

\section{CONCLUSIONS}

The most commonly used types of calving areas across Canada were group and individual calving pens - the 2 types recommended in the Code of Practice. In contrast, the use of tiestalls was also common practice on $26 \%$ of dairy farms surveyed, a practice believed to impair animal welfare. Almost all farms kept records of calving difficulties, which is desirable as these can be used as an indicator of welfare around calving as well as an indicator of prepartum management. Only $7 \%$ of farms had a written calving protocol, which is concerning if the existence of guidelines for calving is an important part of a calving management program designed to reduce the potential welfare problems associated with calving. Some of the management practices, such as assisting every cow at calving, were more prevalent than expected and no recent scientific research has 
been published on their implications, good or bad. This manuscript describes current management practices around calving and will allow the scientific community to plan future research according to the gaps identified. It also underlines management points that are well studied but require better extension programs to transfer the knowledge to producers; for example, the use of protocols for assistance at calving .

\section{ACKNOWLEDGMENTS}

This research was funded by Agriculture and AgriFood Canada (AAFC; Ottawa, Ontario, Canada) and Dairy Farmers of Canada (Ottawa, Ontario, Canada) as part of the Dairy Science Cluster initiative, the Fonds Quebecois de la Recherche sur la Nature et les Technologies (FQRNT; Quebec city, Quebec, Canada)Novalait (Quebec, Quebec, Canada)-Ministère de l'Agriculture, des Pêcheries et de l'Alimentation du Québec (MAPAQ; Quebec, Quebec, Canada), and by Alberta Milk (Edmonton, Alberta, Canada). Stipend support was provided by Valacta Inc (Montreal, Quebec, Canada), the Natural Sciences and Engineering Research Council (NSERC; Ottawa, Ontario, Canada), the Ontario Veterinary College (Guelph, Ontario, Canada) and the Ontario Ministry of Agriculture and Food and Ontario Ministry of Rural Affairs (Guelph, Ontario, Canada). The authors also thank the students and research coordinators who organized and collected the data: Jenny Gibbons and Gemma Charlton (AAFC, Agassiz, British Columbia, Canada), Clémence Nash and Jessica Zaffino (University of Guelph, Guelph, Ontario, Canada), Véronique Bouffard and François Bécotte (Laval University, Quebec city, Quebec, Canada), and Laura Solano and Guiherme Bond (University of Calgary, Calgary, Alberta, Canada).

\section{REFERENCES}

AAFC (Agriculture and Agri-Food Canada). 2012. Statistics of Canada's animal genetics; 2012 edition. AAFC, Ottawa, Ontario, Canada.

Barrier, A. C., M. J. Haskell, S. Birch, A. Bagnall, D. J. Bell, J. Dickinson, A. I. Macrae, and C. M. Dwyer. 2013. The impact of dystocia on dairy calf health, welfare, performance and survival. Vet. J. 195:86-90.

Barrier, A. C., E. Ruelle, M. J. Haskell, and C. M. Dwyer. 2012. Effect of difficult calving on the vigour of the calf, the onset of maternal behaviour, and some behavioural indicators of pain in the dam. Prev. Vet. Med. 103:248-256.

Benzaquen, M. E., C. A. Risco, L. F. Archbald, P. Melendez, J.-J. Thatcher, and W. W. Thatcher. 2007. Rectal temperature, calving-related factors, and the incidence of puerperal metritis in postpartum dairy cows. J. Dairy Sci. 90:2804-2814.

Berglund, B., L. Steinbock, and M. Elvander. 2003. Causes of stillbirth and time of death in Swedish Holstein calves examined post mortem. Acta Vet. Scand. 44:111-120.

Bicalho, R. C., K. N. Galvao, S. H. Cheong, R. O. Gilbert, L. D. Warnick, and C. L. Guard. 2007. Effect of stillbirths on dam survival and reproduction performance in Holstein dairy cows. J. Dairy Sci 90:2797-2803.

Carrier, J. 2007. Behavioral and metabolic observations of dairy cows in the transition period. $\mathrm{PhD}$ dissertation. University of Minnesota, Minneapolis.

Cook, N. B., and K. V. Nordlund. 2004. Behavioral needs of the transition cow and considerations for special needs facility design. Vet. Clin. North Am. Food Anim. Pract. 20:495-520.

Curtis, C. R., J. M. Scarlett, H. N. Erb, and M. E. White. 1988. Path model of individual-calf risk factors for calfhood morbidity and mortality in New York Holstein herds. Prev. Vet. Med. 6:43-62.

DFC-NFACC (Dairy Farmers of Canada and the National Farm Animal Care Council). 2009. Code of Practices for the Care and Handling of Dairy Cattle. Dairy Farmers of Canada, Ottawa, Ontario, Canada.

Fishwick, J. 2011. Welfare issues associated with calving. Cattle Pract. $19: 1-2$.

Frank, N. A., and J. K. Kaneene. 1993. Management risk factors associated with calf diarrhea in Michigan dairy herds. J. Dairy Sci. 76:1313-1323

Gevrekci, Y., Y. M. Chang, K. Kizilkaya, D. Gianiola, K. A. Weigel, and Y. Akbas. 2006. Bayesian inference for calving ease and stillbirth in Holsteins using a bivariate threshold sire-maternal grandsire model. Abstracts of the 8th World Congress on Genetics Applied to Livestock Production, Belo Horizonte, MG, Brazil. WCGALP, Belo Horizonte, Minas Gerais, Brazil.

Kjæstad, H. P., and E. Simensen. 2001. Management of calving in Norwegian cubicle-housed dairy herds. Acta Vet. Scand. 42:131-137.

Lombard, J. E., F. B. Garry, S. M. Tomlinson, and L. P. Garber. 2007. Impacts of dystocia on health and survival of dairy calves. J. Dairy Sci. 90:1751-1760.

McGuirk, B. J., R. Forsyth, and H. Dobson. 2007. Economic cost of difficult calvings in the United Kingdom dairy herd. Vet. Rec. 161:685-687.

McKenna, S. L. B., G. P. Keefe, A. Tiwari, J. VanLeeuwen, and H. W. Barkema. 2006. Johne's disease in Canada Part II: Disease impacts, risk factors, and control programs for dairy producers. Can. Vet. J. 47:1089-1099.

Mee, J. F. 2004. Managing the dairy cow at calving time. Vet. Clin. North Am. Food Anim. Pract. 20:521-546.

Mee, J. F. 2008a. Managing the dairy cow at calving time. AABP Proc. 41:35-43.

Mee, J. F. 2008b. Prevalence and risk factors for dystocia in dairy cattle: A review. Vet. J. 176:93-101.

Proudfoot, K. L., M. B. Jensen, P. M. H. Heegaard, and M. A. G. von Keyserlingk. 2013. Effect of moving dairy cows at different stages of labor on behavior during parturition. J. Dairy Sci. 96:1638-1646.

Schuenemann, G. M., I. Nieto, S. Bas, K. N. Galvao, and J. Workman. 2011. Assessment of calving progress and reference times for obstetric intervention during dystocia in Holstein dairy cows. J. Dairy Sci. 94:5494-5501.

USDA. 2009. Dairy 2007. Part IV: Reference of dairy cattle health and management practices in the United States, 2007. No. N494.0209. Centers for Epidemiology and Animal Health, USDA-APHIS-VS, Fort Collins, CO.

USDA. 2010a. Dairy 2007. Heifer calf health and management practices on U.S. dairy operations, 2007. No. N550.0110. Centers for Epidemiology and Animal Health, USDA-APHIS-VS, Fort Collins, CO.

USDA. 2010b. Dairy 2007. Facility characteristics and cow comfort on U.S. dairy operations, 2007. No. N524.1210. Centers for Epidemiology and Animal Health, USDA-APHIS-VS, Fort Collins, CO.

Vasseur, E., F. Borderas, R. I. Cue, D. Lefebvre, D. Pellerin, J. Rushen, K. M. Wade, and A. M. de Passillé. 2010. A survey of dairy calf management practices in Canada that affect animal welfare. J. Dairy Sci. 93:1307-1315.

Vasseur, E., J. Gibbons, J. Rushen, D. Pellerin, E. Pajor, D. Lefebvre, and A. M. de Passillé. 2015. An assessment tool to help producers improve cow comfort on their farms. J. Dairy Sci. 98:698-708. 